\title{
REBANHOS EM ALDEIAS: INVESTIGANDO A INTRODUÇÃO DE ANIMAIS DOMESTICADOS E FORMAS DE CRIAÇÃO ANIMAL EM POVOS INDÍGENAS NA AMAZÔNIA (RONDÔNIA) ${ }^{1}$
}

\author{
FELIPE FERREIRA VANDER VELDEN ${ }^{2}$ \\ UFSCAr
}

RESUMO: Este artigo discute a introdução de animais domesticados de origem européia em aldeias indígenas na Amazônia, com particular atenção aos grupos em Rondônia, em especial os Karitiana, povo de língua Tupi-Arikém que habita o norte daquele estado. Tendo em vista a história da ocupação do território brasileiro, marcada pela grande narrativa das frentes pastoris', e a recente expansão - material e ideológica - da pecuária pela floresta amazônica, o texto aponta para várias questões referentes à posição desses animais - sobretudo bois - nos universos simbólicos e materiais das populações indígenas, e sugere possibilidades investigativas que interroguem não apenas sobre as experiências já realizadas com a criação animal em aldeias, mas também os desejos e projetos desenhados para que esta seja implantada.

PALAVRAS-CHAVE: Povos indígenas; criação animal; projetos; Karitiana.

ABSTRACT: This paper discuss the introduction of European domestic animals in indigenous villages in the Amazon, with particular stress on groups in Rondonia, specially the Karitiana, a Tupi-Arikém-speaking people that lives in the north of that state. In what concerns the history of Brazilian territorial conquest, marked by the 'frentes pastoris"' great narrative, and the present expansion - material and also ideological - of husbandry throughout Amazonia, this article points to many questions about the position of these animals - above all cattle - in indigenous peoples' symbolical and material universes. Suggests new investigative possibilities, that inquires not only implemented experiences with animal husbandry in indigenous villages, but also desires and projects designed to future implementations.

KEYWORDS: Indigenous peoples; animal husbandry; projects; Karitiana.

\footnotetext{
${ }^{1}$ Este artigo foi apresentado em seminário do Projeto Temático Redes Ameríndias do Núcleo de História Indígena e do Indigenismo (NHII) da Universidade de São Paulo (USP), em setembro de 2010. Agradeço aos comentários e sugestões de Ana Martha Yano, Renato Sztutman, Beatriz Perrone-Moisés, Íris Araújo, Joana Cabral, Igor Scandiuzzi e Valéria Macedo.

${ }^{2}$ Mestre e Doutor pelo Programa de Pós-Graduação em Antropologia Social da Universidade Estadual de Campinas (UNICAMP), atualmente é Professor Adjunto I do Departamento de Ciências Sociais da Universidade Federal de São Carlos (UFSCar). E-mail: felipevelden@yahoo.com.br .
}

Espaço Ameríndio, Porto Alegre, v. 5, n. 1, p. 129-158, jan./jun. 2011. 


\section{Animais circulando entre culturas e saberes}

Ainda que clássico na disciplina antropológica (ver, por exemplo, Evans-Pritchard (1999), Lévi-Strauss (1997), Leach (1983); Tambiah (1969), Sahlins (2003), entre muitos outros), o estudo das relações entre humanos e animais continua a demandar um esforço realmente concentrado para uma melhor compreensão de toda a sua variedade, riqueza etnográfica e complexidade. Provas disso são as recentes contribuições de renomados antropólogos, que focalizam as interações - materiais e simbólicas - entre seres humanos e não humanos como forma privilegiada de entendimento das relações sociais, da socialidade e da sociabilidade, entendidas, agora, com sentidos e limites ampliados.

Pensemos, por exemplo, nos últimos trabalhos de Claude LéviStrauss (2004), ao se dedicar aos desafios colocados pela "Síndrome da Vaca Louca" e dos impactos de grande profundidade que as intervenções das sociedades industriais sobre os animais vêm trazendo. Pensemos, também, na percepção de que as fronteiras entre o humano e o não humano não são estanques, mas devem ser não só analisadas caso a caso como também politicamente negociadas em vários contextos. Assim, vários autores vêm se dedicando a reconsiderar as fronteiras entre natureza e cultura, propondo que a antropologia deve levar com seriedade a inclusão de seres não humanos na composição dos agrupamentos sociais. Entre outros, teóricos como Donna Haraway (2003 e 2008) e suas naturecultures; Bruno Latour (1997 e 2004) e seus híbridos; Tim Ingold (2000) com noções como forma de vida, movimento, rastro, inscrição e engagement, que buscam conectar humanos e não humanos nas "paisagens" (/andscapes) do mundo. Mais especificamente no contexto das terras baixas sul-americanas, destacamos as seminais contribuições de Eduardo Viveiros de Castro (1996 e 2002) e seu perspectivismo multinaturalista ameríndio; Philippe Descola (1994, 1998, 2002 e 2005) e seu animismo; e Eduardo Kohn (2007) e sua proposta de uma antropologia da vida - todos esses autores recusam divisões estanques entre os seres e questionam a 
universalidade da discrição entre domínios do natural e do cultural, requerendo uma reflexão mais apurada sobre as modalidades de relações entretecidas pelas criaturas que habitam o planeta, e argumentando que só a pesquisa empírica pode informar sobre as distintas modalidades de produção da diferença. Ademais, defendem que a separação nítida e clara entre seres naturais e seres culturais é um produto singular de uma formação social e histórica específica, que permite, por meio desta mesma cesura, modalidades de apropriação material e simbólica dos não humanos que contrastam fortemente com aquelas encontradas em distintos contextos históricos e etnográficos (Cf. THOMAS 2001). Com isso, subscrevem a formulação de John Knight (2005), em introdução de recente coletânea, de que nosso interesse deve ser:

(...) in animals as subjects rather than objects, in animals as parts of human society rather than just symbols of it, and in human interactions and relationships with animals rather than simply human representations of animals (KNIGHT, 2005, p. 1, itálicos no original).

Muito por conta desses novos esforços analíticos, o tema vem se revestindo também de uma crescente relevância política, a partir da constatação mais e mais reforçada de que compartilhamos o mundo com uma pletora de seres diferentes de nós, e que precisamos tomar seriamente esta premissa, de modo a redesenhar os modelos de socialidade $^{3}$ que desejamos para o presente e o futuro. Esta constatação vem sendo feita também por ambientalistas, defensores de direitos humanos, ativistas de direitos animais e pensadores que, nos mais diversos campos do conhecimento (Biologia, Ecologia, Filosofia, Sociologia, História), refletem sobre a labilidade das categorias humano/animal e sobre a necessidade premente de revisão nos modos como os humanos nos relacionamos com os demais entes que povoam o planeta.

\footnotetext{
${ }^{3}$ Falo em modelos de socialidade tendo em mente as contribuições de Bruno Latour (1997 e 2004), com seus híbridos natural-culturais, e de Donna Haraway (2003 e 2008), com sua noção de Naturezacultura (natureculture). As ideias de Tim Ingold (2000) e algumas de suas noções - como engagement, rastro, movimento e forma de vida - vão no mesmo sentido. Os trabalhos de Eduardo Viveiros de Castro (1996) e de Philippe Descola (1994, 1998, 2002 e 2005) sugerem considerações semelhantes no contexto etnográfico das terras baixas sul-americanas.
} 
FELIPE FERREIRA VANDER VELDEN - Rebanhos em aldeias...

Meu trabalho tem procurando alinhar-se com este interesse renovado pelas relações entre humanos e animais. Na minha tese de doutorado (VANDER VELDEN, 2010a), debrucei-me sobre as múltiplas relações entretecidas entre os índios Karitiana ${ }^{4}$ e o que eles chamam de animais de criação ${ }^{5}$, especialmente aqueles introduzidos após o contato com os brancos (cavalos, bois, cachorros, gatos, galinhas, coelhos, porcos, entre outros 6 ), que se deu de forma mais intensa a partir da segunda metade do século XIX. Entre outras coisas, discuti, ali, uma questão que vem sendo muito debatida entre os índios e diferentes órgãos formuladores de políticas indigenistas, locais, nacionais e internacionais: os projetos para a introdução da criação sistemática de animais (sobretudo piscicultura, bovinocultura e avicultura7) entre os Karitiana, uma vez que não há, atualmente, iniciativas deste tipo implantadas em suas três aldeias. Os Karitiana, contudo, manifestam grande interesse em iniciá-las, mas, por outro lado, reconhecem as numerosas dificuldades envolvidas. No meu texto, procurei discernir alguns dos descompassos - técnicos, econômicos, sociais e cosmológicos - que têm papel nas trajetórias tomadas até o momento por esses debates, incluindo-se aí os fracassos que já foram experimentados no passado: uma criação de cabras e uma de galinhas de granja (criadas em confinamento), que falharam por razões várias ${ }^{8}$, e

\footnotetext{
${ }^{4}$ Os Karitiana são aproximadamente 350 pessoas, que vivem em três aldeias, uma delas no interior da Terra Indígena Karitiana (demarcada e homologada), outras duas nos limites desta; a Terra Indígena localiza-se integralmente no município de Porto Velho, norte do estado de Rondônia. Falam uma língua do tronco Tupi, da família Arikém. Para dados atualizados, ver Vander Velden (2010a, p. 46-107).

5 Grosso modo, os Karitiana agrupam sob o termo animal de criação (animal by'edna) o que as sociedades industriais ocidentais denominam animais domésticos ou domesticados: esta categoria, no ocidente, inclui, e distingue, os animais de estimação ou mascotes (pets) e os animais de criatório ou de abate.

${ }^{6}$ Esses animais domesticados de origem europeia, trazidos pelos colonizadores e introduzidos nas aldeias indígenas, são aqui referidos como animais exóticos, exógenos, introduzidos ou adventícios.

${ }^{7}$ Chamo de criação sistemática a manutenção permanente (e em permanente reprodução) de um coletivo de animais de acordo com as técnicas preconizadas pela zootecnia, pela veterinária, e por um conjunto de práticas e saberes mais difusos denominados pecuária ou criação; e com a finalidade de utilização contínua desses animais e seus subprodutos (tração, transporte, investimento, ocupação territorial, alimentação, adubação, matérias-primas etc) por meio do controle e da gestão de seus corpos vivos ou mortos.

${ }^{8}$ Explorei estas razões na minha pesquisa de doutoramento já citada, e elas são um tanto complexas para serem resumidas aqui. De modo grosseiro, os principais motivos que levaram ao fracasso dos projetos de criação entre os Karitiana foram a recusa de uma atividade econômica comunitária (em uma sociedade em que a produção se organiza nas unidades familiares) e a incorporação desses animais no conjunto de relações sociais que caracterizam as interações entre humanos e não humanos na Amazônia: deste modo, a exploração desses seres - como alimento, o que se pretendia originalmente - tornou-se algo impossível, já que os animais cuidados pelas pessoas eram familiarizados e se tornavam "como filhos".
}

Espaço Ameríndio, Porto Alegre, v. 5, n. 1, p. 129-158, jan./jun. 2011. 
FELIPE FERREIRA VANDER VELDEN - Rebanhos em aldeias...

foram desativados. Diz-se que as cabras comeram uma erva venenosa e morreram em grande quantidade, ao passo que as galinhas confinadas - percebidas como muito diferentes daquelas criadas nos terreiros das residências - deixadas pelos Karitiana, que não as alimentavam, acabaram também morrendo. No entanto, a ausência de animais de rebanho ou de criatório - notadamente bovinos e equinos - entre os Karitiana não permitiu, evidentemente, uma investigação mais aprofundada sobre a criação de animais, e eu terminei por concentrarme nos animais de criação.

Mas se não havia bois e cavalos, havia (e há) muito discurso sobre eles 9 . Meu interesse nesses animais ausentes - bois, sobretudo também é direcionado pelo impacto presente que a pecuária vem produzindo na Amazônia e também em outros ecossistemas brasileiros, como os Cerrados do Brasil Central: não só as paisagens como um todo vêm sendo continuamente devastadas para a introdução de pastagens e gado (FEARNSIDE, 1989; HECHT, 1993; SMERALDI e MAY, 2008 e 2009), mas Rondônia em particular vem cultivando a imagem de uma nova fronteira agropastoril, acompanhando a pujança alcançada pelo agronegócio no país como um todo ${ }^{10}$. Vários estudos, em diversas regiões amazônicas, destacam as razões que tornam a criação de gado (e de outros animais) bastante atrativa para fazendeiros e colonos, implicando em bens tanto materiais - aumento de empregos, acesso a investimentos, incremento de renda, participação nas cadeias produtivas regionais e nacionais - quanto simbólicos - garantia de posse da terra ("terra com gado é terra com dono", diz-se no interior do Brasil), status da posição de fazendeiro/pecuarista, satisfação geral derivada do acesso à terra e da relativa segurança econômica (Cf. BASTOS DA VEIGA et al, 2004; TONI et al, 2007).

Mas qual é a posição dos variados povos indígenas que, Brasil

Ademais, os Karitiana nunca compreenderam a necessidade de alimentar esses animais. Daí o desinteresse dos Karitiana por aqueles projetos, o que foi agravado pela falta de treinamento técnico em criação animal, algo que os índios reclamam até hoje.

9 Até onde se sabe, nunca houve bois na aldeia Karitiana, embora projetos de pecuária bovina tenham sido desenhados e apresentados para sua Terra Indígena desde os anos 80, primeiro com financiamento do POLONOROESTE, e nos anos seguintes sob os auspícios da FUNAI regional. Eu encontrei um burro (asinino) na aldeia Kyõwã em 2003, e soube de outro, morto alguns anos antes. Em 2006 havia uma égua muito mansa, pertencente ao vice-cacique, e empregada como montaria por alguns poucos jovens.

${ }^{10}$ Um adesivo distribuído nas grandes feiras agropecuárias do estado em meados de 2009 defende:

"Rondônia: estado natural da pecuária". 
FELIPE FERREIRA VANDER VELDEN - Rebanhos em aldeias...

afora, também foram e são atingidos não apenas pelas frentes de penetração pastoril (as do passado, que abriram vastos espaços à penetração colonizadora, e as de hoje, técnica, ideológica e financeiramente orientadas), mas ainda pelos discursos oficiais e populares que valorizam a pecuária e o pecuarista? O caso Karitiana que pesquisei demonstra que, mesmo sem gado, este povo é fortemente atraído pelos bens econômicos e simbólicos que a pecuária propaga poder oferecer: os Karitiana parecem almejar não o gado por ele mesmo, mas a pecuária como forma de se converterem em fazendeiros, pois esta é uma figura de grande poder e prestígio na região ${ }^{1}$ (VANDER VELDEN, 2010a). No entanto, a ausência de projetos efetivamente instalados não permitiu, obviamente, avaliar os impactos práticos e simbólicos provocados por esses animais e os sistemas técnicos e conceituais que devem acompanhar sua introdução (Cf. DESCOLA, 2002).

Há alguns anos, em 2006, a EMATER-RO, em parceria com a FUNAl, anunciou a cessão de dez vacas e mais um touro reprodutor para os Karitiana da aldeia Kyõwã (a maior e mais antiga aldeia, situada quase no centro da Terra Indígena Karitiana). Os índios demonstraram entusiasmo com a proposta, ainda que os homens mais velhos, recordando os antigos fracassos com as galinhas e cabras, asseverassem que sem o treinamento técnico adequado a criação de bois não daria certo: criados soltos, os animais invadirão e destruirão roçados, o que será fonte de inevitáveis querelas entre vizinhos (como acontecia com os cavalos que viviam em Kyõwâ); por isso, é preciso saber cuidar dos animais e, dizem, somente "fazendeiro é que sabe" . O projeto, enfim, não vingou, e, em 2009, quando retornei ao campo, havia um novo projeto, agora de implantação de piscicultura em tanques artificiais, destinados a abrigar três espécies de peixes, entre eles a tilápia, espécie exótica (originária da África oriental). O croqui

\footnotetext{
${ }^{11}$ Os limites norte e leste da Terra Indígena Karitiana são tomados por fazendas de gado, que devastaram a mata nativa e vêm causando vários problemas aos índios, desde a ocupação irregular de trechos de suas terras até o barramento de igarapés a jusante da área, gerando escassez de água e pescado. Vários desses fazendeiros, por outro lado, estão frequentemente envolvidos com a política regional e estadual e, no jogo político paternalista do interior do Brasil, é comum que adulem os índios com presentes e benesses (inclusive com cabeças de gado ou carne de animais abatidos), o que, juntamente com carros caros, helicópteros e adereços vistosos (roupas, relógios, correntes de ouro), funcionam como eficientes formas de exibição de poder. O próprio governador de Rondônia é visto como o mais poderoso fazendeiro, com seu chapéu diuturnamente na cabeça e sua contumaz arrogância.
} 
FELIPE FERREIRA VANDER VELDEN - Rebanhos em aldeias...

dos tanques acabara de ser concluído, e o chefe do posto, entusiasmado, apenas aguardava a verba para dar início às obras, o que não havia ocorrido até eu deixar Rondônia, em agosto daquele ano.

Entretanto, a importância dos bovinos e da pecuária para os Karitiana - mesmo que largamente resultante de uma imagem do pecuarista e da criação animal de grande porte - levou-me a refletir sobre o quão pouco sabemos sobre a introdução desses animais e dos processos para administrá-los entre populações indígenas. Os estudos históricos demonstram, há tempos, a intensa circulação de animais entre a América do Sul e a Europa (MARCHANT, 1943; CROSBY, 1972; MELVILLE, 1999), e há certo consenso em que a Europa nos deu especialmente animais, ao passo que a América cedeu novidades em matéria vegetal (DESCOLA, 1996) ${ }^{12}$. Outras pesquisas vêm destacando a velocidade com que as espécies introduzidas pelos colonizadores se espalharam pelas terras baixas sul-americanas: a rapidez da ocupação dos sertões pelas frentes pastoris (CAPISTRANO DE ABREU, 1988; D. RIBEIRO, 1996) é uma das grandes narrativas da ocupação do Brasil; outras espécies animais de menor porte também parecem ter-se difundido velozmente entre diferentes populações indígenas espalhadas pelo território, como é o caso das galinhas domésticas (NORDENSKIÖLD, 1922; VANDER VELDEN, 2010c), possivelmente por rotas de circulação de bens - que incluíam cães e papagaios - que cortavam largas áreas do continente, sendo melhor conhecidas aquelas na região das Guianas (Cf. BARBOSA, 2005).

No entanto, sabemos quase nada das inflexões locais do aparecimento desses novos seres e das novas relações entre humanos e animais (a pecuária, o curral, as técnicas de criação e controle). Temos algumas considerações sobre a reação dos povos indígenas aos grandes herbívoros, matando-os como caça ou como símbolos da presença esmagadora dos fazendeiros brancos (Cf. MELATTI, 1967), ou adotando-os como recurso alimentar e econômico ou como forma de defesa de territórios (SANTILLI, 1994). Resta ainda, contudo, investigar

\footnotetext{
${ }^{12}$ Esta conclusão deve ser matizada, pois pesquisas recentes têm demonstrado a intensa circulação de animais americanos na Europa a partir do século XVI (ROBBINS, 2002; FRANÇOZO, 2009). Keith Thomas (2001) já havia sugerido que o hábito de criar pets em íntima convivência com humanos emergiu no Velho Mundo influenciado pelas descrições das relações entre os índios e seus animais de estimação.
} 
em detalhe as formas como esses seres e essas modalidades de criação animal foram (e são) absorvidas e incorporadas pelas diferentes sociedades indígenas que com eles entraram em contato, seja no passado, seja atualmente, no cenário de difusão da pecuária Amazônia adentro e da extrema valorização do agronegócio no Brasil contemporâneo.

O que sugere este trabalho é a necessidade de investigar a difusão do gado bovino - e de outros grandes herbívoros de rebanho, como cavalos, cabras e ovelhas - por entre as populações indígenas, de modo a buscar reconstituir o histórico da origem e da penetração desses seres (como fiz para o caso Karitiana13) e as formas de sua adoção e incorporação nas práticas cotidianas, produtivas e rituais e nos seus universos míticos e simbólicos. Para isso, devemos inicialmente mapear os grupos indígenas que dispõem de rebanhos (por mínimos que sejam) ${ }^{14}$, para então partirmos para o estudo detalhado da posição desses animais nas cosmologias nativas, bem como dos impactos trazidos por esses animais e as formas de sua criação. Esses impactos são tanto de ordem simbólica quanto de ordem prática, no que se referem a alterações nos sistemas econômicos e de ocupação e organização dos territórios (DESCOLA, 1982), e a modificações ambientais e nas condições sanitárias locais (Cf. LEITE, 2007).

\section{Difusão, introdução e criação}

No panorama das relações entre povos indígenas e animais introduzidos com o contato, duas modalidades de aparecimento destes últimos interessam sobremaneira compreender: a difusão dos animais antes da chegada dos homens, e a introdução deliberada deles nas aldeias.

Em primeiro lugar, o próprio aparecimento desses seres

\footnotetext{
${ }^{13}$ Cf. Vander Velden (2010a, p. 76-87).

14 Os dados devem vir de fontes variadas: informações constantes nos setores de desenvolvimento econômico da FUNAI, fichas sobre condições sanitárias aplicadas pela FUNASA, listas de projetos de desenvolvimento elaboradas pela FUNAI e ONG's, recenseamentos agropecuários municipais, estaduais ou nacionais, informações de pesquisadores em campo, entre outros.
} 
FELIPE FERREIRA VANDER VELDEN - Rebanhos em aldeias...

exógenos e exóticos entre as sociedades nativas das terras baixas da América do Sul demanda consideração teórica pela Antropologia e a Etnologia. Existem vários estudos detalhados que abordam a história da expansão geográfica e populacional desses animais pelo continente e suas consequências ecológicas, sociológicas e econômicas (CROSBY, 1972; MELVILLE, 1999; METCALF, 2005). No entanto, ainda há poucos estudos que focalizam esses eventos no detalhe, explorando os impactos e as alterações materiais e simbólicas que a irrupção de novos seres no cotidiano dos povos nativos acarretou. No caso da expansão da pecuária como atividade econômica, tudo o que temos é uma narrativa mestra da veloz extinção dos povos que com ela tiveram contato ${ }^{15}$. Contudo, várias populações vêm tomando contato com esses seres nos últimos séculos, e em muitas delas tais animais encontraram espaço, onde tomam parte tanto em sistemas econômico-produtivos quanto em contextos míticos e rituais de grande importância.

No entanto, mesmo no bojo de um razoável interesse recente da Antropologia pelos animais domésticos/domesticados em variados universos sociais e etnográficos (Cf. DIGARD, 1990; SHANKLIN, 1985; PODBERSCECK, PAUL e SERPELL, 2000; ROTHFELS, 2002; KNIGHT, 2005), a etnologia americanista, curiosamente, pouco esforço dedicou a compreender a posição desses seres nas aldeias indígenas. Isso seria, possivelmente, manifestação daquilo que Joanna Overing (1999, p 8485) chamou de "desinteresse antropológico pela domesticidade e pelo cotidiano", que se reflete na pouca atenção etnográfica aos contextos da intimidade e das relações sociais cotidianas, ao contrário do peso conferido às relações interétnicas, ao comércio, à guerra, aos rituais de canibalismo. É certo que existem alguns (poucos) estudos que focalizam os assim chamados xerimbabos, os animais nativos cujos filhotes são capturados na floresta para serem amansados/familiarizados e criados como pets (ERIKSON, 1987, 1988 e 2000; CORMIER, 2003). Entretanto, os animais introduzidos pelos europeus mereceram pouquíssima atenção dos pesquisadores trabalhando entre povos indígenas - descontadas as referências anedóticas, em geral no início dos textos -, e isso mesmo em contextos nos quais as espécies adventícias alcançaram números expressivos e

\footnotetext{
${ }^{15}$ Cf. as frentes pastoris de Darcy Ribeiro (1996).
} 
clara importância econômica, social, política, histórica e simbólica: penso, entre outros, nos Kadiweu (os famosos "índios cavaleiros"16), nos Bakairi em Mato Grosso (PINA DE BARROS, 2003), nos Guajiro (Wayuu) na fronteira venezuelano-colombiana (PICON, 1983), nos povos nativos dos Pampas, do Chaco e das planícies da bacia do Prata (GALVÃO, 1963; PALERMO, 1986), e nos grupos nos campos naturais do escudo das Guianas, como os Macuxi e os Wapishana (SANTILLI, 1994; FARAGE e SANTILLI, 1992).

A presença significativa de animais domesticados introduzidos com a colonização nas aldeias - amplamente atestada, frequentemente en passant pelas etnografias - nos leva à segunda modalidade de aparecimento dos animais adventícios, que se refere aos projetos de introdução intencional - intermediada pela ação humana - de espécies não nativas e de sua criação.

Desde os primórdios da colonização do Brasil17, mas com maior intensidade a partir das leis indigenistas do Império (Cf. RAMOS, 1999), e, sobretudo, após a criação do Serviço de Proteção ao Índio (Cf. CARNEIRO DA CUNHA, 1992; SOUZA LIMA, 1995), a transformação dos povos indígenas em agricultores e criadores sedentários e ordeiros foi uma preocupação constante das autoridades ocupadas com estas populações. Neste processo, a criação animal - notadamente a pecuária bovina, mas também a criação de pequenos animais (suínos, caprinos, aves) - foi um dos aspectos destacados, muito em função do valor atribuído pelas populações ibéricas à pecuária como modelo de ocupação racional de terras e de civilização de territórios "se/vagens" e de grupos sociais "bárbaros" (Cf. BARETTA e MARKOFF, 1978; FEARNSIDE, 1989). Atualmente, os incentivos à implementação da criação animal em escala ampliada nas aldeias indígenas continuam em voga, agora subsumindo um viés civilizacionall 8 sob discursos como o da escassez de caça e o da segurança alimentar (Cf. LEITE, 2007; SALGADO, 2007) ${ }^{19}$.

\footnotetext{
${ }^{16}$ Cf. Bertelli (1987).

${ }^{17}$ Cf. o caso do vale do rio Branco, onde o gado foi deliberadamente introduzido no final do século XVIII em Santilli (1994) e Farage e Santilli (2009, p. 24-25).

${ }^{18}$ Os estudos de Virginia Anderson (1994, 2002 e 2004) demonstram de modo contundente esta intenção civilizacional da pecuária quando levada para a Nova Inglaterra, e seus efeitos sobre a paisagem e as populações indígenas na região, julgados benéficos pelos colonizadores. Cf. também Cronon (1983).

${ }^{19}$ Discuti longamente essas questões em Vander Velden (2010a e 2010c).
} 
Este discurso vem se cruzando, pelo menos nas últimas quatro décadas, com orientações oficiais e não oficiais que dirigem as frentes colonizadoras que vêm devastando muitas áreas naturais do país - em especial a região amazônica - para a instalação da criação bovina em escala comercial. Leve-se em conta que a pecuária tem um forte apelo simbólico aliado à crescente importância econômica da atividade no Brasil, que possui o maior rebanho bovino do mundo e já é o maior exportador de carne entre todos os países (BARBOSA e MOLINA, 2007). O destaque alcançado pela pecuária no país - hoje, mas ao que parece desde o início da colonização, pois bovinos já haviam sido trazidos para o litoral da América portuguesa desde pelo menos 1531 (Cf. VANDER VELDEN, 2010a, p. 40) - parece ter um forte apelo entre os formuladores de políticas públicas para os povos indígenas, sem contar os próprios índios, como pude constatar entre os Karitiana (VANDER VELDEN, 2010a).

Que a maior parte dessas iniciativas de introdução do gado em aldeias indígenas tenha falhado parcial ou completamente 20 (DESCOLA, 1982; QUEIXALÓS, 1993; MACDONALD, 1997; ERIKSON, 1998; GUERRA, 2008, p. 157-158) já o percebera Peter Schröder:

No Brasil, as experiências com a pecuária bovina em terras indígenas na Amazônia Legal geralmente foram desestimuladoras, pois elas se fundamentaram, na maioria dos casos, em pressupostos errôneos sobre as culturas indígenas e necessitaram de grandes mudanças culturais da organização econômica indígena (SCHRÖDER, 2003, p. 95-96).

Ademais, tal cenário nos leva a questionar várias das premissas que podem estar ocultas na linguagem dos projetos para povos indígenas (INGLEZ DE SOUZA et al, 2007), tão em voga no momento contemporâneo, mas que guardam relações complexas entre os desejos

\footnotetext{
${ }^{20}$ Aqui me baseio numa distinção, apresentada na tese de doutorado (VANDER VELDEN, 2010a), entre o fracasso completo ou absoluto dos projetos de criação animal - nos quais a iniciativa foi totalmente abandonada e os animais morreram, foram comidos, abatidos ou recolhidos - e o fracasso relativo dos mesmos - quando os animais permanecem nas aldeias, mas por motivos diferentes daqueles almejados pelos projetos, não sendo aproveitados ou utilizados segundo as diretrizes originais: por exemplo, o caso estudado por André Martini (2008) no rio Negro, onde o projeto de criação de peixes, destinado a aumentar a oferta deste alimento, fracassou porque os índios não consumiam o pescado - por razões simbólicas analisadas pelo autor -, mas vendiam-no para adquirir frangos congelados originários de Manaus, muito mais caros.
} 
FELIPE FERREIRA VANDER VELDEN - Rebanhos em aldeias...

dos índios e as intenções dos planejadores. De fato, uma parte substancial das demandas dos grupos indígenas por projetos de etnodesenvolvimento centram-se na requisição de criação animal de várias espécies, exóticos e nativos (RIBEIRO DE ALMEIDA, 2008). Não obstante, é curioso notar que iniciativas que buscam aliar desenvolvimento com as formas nativas de organização social e econômica, identidade, ocupação territorial, relações com o ambiente e gestão política - essas iniciativas acabam por recorrer a uma forma de produção material (que também é uma modalidade de relação entre humanos e animais) que é, em princípio, estranha às culturas indígenas no Brasil: com efeito, os índios nas terras baixas sul-americanas não domesticaram animais no sentido estrito do termo (DESCOLA, 2002), e muito menos possuíam criação animal de forma sistemática. Os problemas de muitos grupos com a criação de animais - entre eles, o estranhamento dos Karitiana diante das "galinhas brancas, de granja", confinadas em um galinheiro e necessitando de alimentação provida por humanos, além de medicamentos, hormônios e outros procedimentos técnicos - possivelmente deriva de descompassos cosmológicos derivados da ausência da experiência com a relação de domesticação/controle - daí os tais "pressupostos errôneos" de que fala Peter Schröder (2003).

Eu não quero dizer, com isso, que as diversas sociedades indígenas brasileiras sejam atavicamente impermeáveis à introdução de animais domesticados e de sua criação: isso seria negar não só a capacidade de transformação e adaptação sociocultural , como também a eficácia do estudo e do treinamento técnico (Cf. GORDILLO, 2006). Sugiro, apenas, que relativizemos a ampla divulgação da criação animal como forma de garantia das condições alimentares/nutricionais e da saúde e do bem-estar das populações indígenas, bem como as razões que levam os índios a se interessar pelo gado: como parece ser o caso entre os Karitiana, ainda que reclamem da escassez de caça e da carência de alimentos (carne, em especial), este grupo parece querer bois porque, acima de tudo, almejam a figura (o poder e o prestígio) do fazendeiro, o que se coaduna com a força simbólica que tem a pecuária no Brasil - força que aumenta na Amazônia concomitantemente ao crescimento vigoroso do agronegócio naquela região. 
Mas, com tudo isso, o que significam esta difusão do gado pelo interior do Brasil e sua adoção por vários povos indígenas? Como as formas de controle dos animais de rebanho e as técnicas de criação pois, sabemos, existem currais em aldeias, assim como comércio e abate de reses (PINA DE BARROS, 2003), e vários grupos adotaram cavalos como montaria (os Karitiana, inclusive) e bois como animais de tração, além de variadas técnicas de manejo do gado21 - foram adotadas e ressignificadas por estes grupos? Quais impactos tiveram nos sistemas produtivos, nas relações com outros seres, na mitologia, na arte (SIQUEIRA JR., 1992; MACÊDO, 2006)? Que posição esses animais e suas relações com os humanos e com outros seres assumiram nas cosmologias e práticas sociais indígenas?

Em um interessante artigo no qual discute as razões pelas quais as populações indígenas nas terras baixas sul-americanas não desenvolveram a domesticação animal (em sentido estrito, a seleção, criação e reprodução sistemática de certas espécies animais em convívio intenso com humanos e sob controle destes), Philippe Descola (2002) sugere que a adoção de "animais domésticos europeus" por estas sociedades deu-se

(...) sem grandes dificuldades, pois as modalidades técnicas e ideológicas do tratamento do animal foramIhes, em grande parte, transmitidas com o animal ele mesmo e implicavam somente alguns rearranjos nas taxonomias (DESCOLA, 2002, p. 107).

A afirmação de Descola soa estranha, caso seja lida a partir de certa noção de cultura corrente na Antropologia (SAHLINS, 1985): como uma população pode receber todo um sistema técnico e ideológico ("pacote tecnológico" nas palavras de Turbay (2002, p. 102)) sem adaptá-lo à sua estrutura de sentidos - sua cultura - preexistentes? Todo um modelo de relação com o animal é adotado sem que o sistema se rearranje, e sem que essas "formas novas" sejam relidas pela cosmologia, implicando apenas em "rearranjos taxonômicos"? É certo que inúmeros povos indígenas adotaram os animais exógenos, e muitas das técnicas adventícias para com eles se relacionarem; não obstante, a

${ }^{21}$ Sobre os Kadiwéu ver Bertelli (1987) e ISA e Moreau (2000). 
questão é saber qual o significado que essas práticas assumiram nos universos sociocosmológicos nativos. É certo, ainda, que vários grupos adotaram as regras de comestibilidade vinculadas pela cosmologia ocidental a esses novos seres: com efeito, os Karitiana, como seus vizinhos não índios, comem carne de bois, porcos e galinhas, mas nunca de cavalos, cachorros e gatos (VANDER VELDEN, 2010b). Mas estarão mesmo simplesmente reproduzindo regras e gostos alimentares importados, ou refletindo sobre o estatuto desses seres? Aqui é preciso acrescentar que os Karitiana comem a carne dessas espécies somente em certos contextos (Cf. JARA, 2002), posto que, ao que parece, jamais comem seus próprios bois, porcos e galinhas de criação, como mostrei em Vander Velden (2010a). Talvez uma investigação sobre práticas alimentares erre o alvo ao se concentrar em espécies ou categorias animais, e não na qualidade das relações estabelecidas entre os humanos e determinados animais individuais em contextos específicos e determinados 22 .

No meu trabalho (VANDER VELDEN, 2010a) busquei mostrar que a adoção do cão implicou uma considerável reordenação no modelo indígena de interações com os outros seres do cosmos, produzindo um sistema de relações entre humanos e animais muito distinto daquele vigente entre os não indígenas vizinhos (e que levaram os cães aos Karitiana). Estes seres entraram no sistema nativo de classificação pela via dos xerimbabos, mas introduziram nele algo de uma potência estrangeira - a mesma dos brancos e de suas manufaturas - que os distingue desses mesmos xerimbabos: ambos vêm de fora - da floresta num caso, da cidade no outro -, mas os cachorros, pelo fato de se reproduzirem nas aldeias e de apresentarem outros hábitos anômalos e associais, representam uma espécie de irrupção de potência destrutiva e predatória no interior da sociabilidade idealmente pacífica e ordeira das aldeias. É por esta razão que os cães são obaky by'edna, "onças de criação", termo que é quase uma contradição. Assim, se o rearranjo taxonômico pôs cães ao lado das onças, o conjunto das relações práticas entre homens e cachorros levou à constituição de laços de natureza "ideológica" muito diferentes daqueles entretecidos entre homens e cães nas sociedades ocidentais (Cf. SERPELL, 1996; LORENZ,

\footnotetext{
${ }^{22}$ Como quer Knight (2005), em sua introdução.
} 
1997; SCHWARTZ, 1997)23.

Descola está, aqui, pensando mesmo no cachorro, ainda que faça referência generalizante aos "animais domésticos europeus". Mas se sua afirmação sobre a "adaptabilidade" do cão suscita meus comentários, o que dizer de sua aplicação a um conjunto de espécies cuja relação com os humanos que os trouxeram para o Novo Mundo (os colonizadores europeus) é destacadamente diversa daquelas encontradas nas terras baixas sul-americanas? Refiro-me aos grandes ruminantes, os animais de rebanho, pastoreio ou criatório: bois, cabras, cavalos, burros, ovelhas, búfalos. Descola continua, no mesmo texto, afirmando que em várias culturas da América do Sul tropical ocorre a coexistência:

(...) de duas modalidades diferentes de objetivação de duas classes de animais distintos (a caçaamansamento dos animais passíveis de serem caçados e a criação de animais domésticos europeus) (DESCOLA, 2002, p. 108).

O autor aponta para uma diferença nas espécies animais - nativos (caçados e amansados) e introduzidos (criados) -, termos que podem eventualmente circular pelas duas relações distintas: por vezes um animal criado que foge é convertido em caça e, desta forma, abatido sem maiores entraves simbólicos (Cf. VANDER VELDEN, 2010a) ${ }^{24}$.

Esta circulação de termos por diferentes relações (modalidades de objetivação) me parece indicar que estas duas relações podem não ser assim tão diferentes, e o trabalho necessário será investigar como elas se interpenetram e se influenciam mutuamente no conjunto de práticas e saberes técnicos e ideológicos indígenas. As pesquisas devem

\footnotetext{
${ }^{23}$ Da mesma forma, discordo da afirmação de Turbay (2002, p. 102 - meu grifo) de que "los indígenas asimilaron sin dificultad la cría de perros, gallinas y cerdos como parte del paquete tecnológico que llegó asociado a outra ideologia”. Meus dados sobre os Karitiana (VANDER VELDEN, 2010) indicam que a adoção desses seres não só não foi isenta de descompassos e temores, como não penso ser possível dizer que a criação (cría) desses seres foi plenamente adotada, uma vez que necessitamos qualificar precisamente o que se entende por criação animal. Ademais, os casos etnográficos são por demais complexos e variados, e não me parecem autorizar uma conclusão tão definitiva como quer a autora (e Philippe Descola).

${ }^{24}$ Descola afirma que a transferência inversa - a da conversão do animal de caça em animal domesticado/criado - não foi registrada na América tropical. O caso demanda melhores estudos, caso pensemos na questão ainda não resolvida do pato-almiscarado (muscovy duck, Cairina moschata), bem como em outras notícias de grupos que mantinham animais em confinamento - tartarugas, porcos-domato - para serem abatidos conforme a necessidade ou conveniência (DONKIN, 1985 e 1989; GILMORE, 1997). Os projetos recentes de implantação da criação de animais nativos da fauna brasileira em aldeias indígenas também podem ser avaliados a partir desta observação.
} 
focalizar a criação de animais exógenos, ou seja, as relações materiais e simbólicas que as populações indígenas estabelecem com os animais de rebanho ou criatório introduzidos pelos europeus. Mais do que isso, deve-se investigar como as sociedades indígenas nas terras baixas receberam e adotaram a criação sistemática de animais - aqui no sentido estrito, de pecuária - tal como introduzida pelos brancos ao longo da história do contato. Deste modo, buscar compreender como as diversas cosmologias nativas adotaram e transformaram as "modalidades técnicas e ideológicas do tratamento do animal" (nas palavras de Descola) implicadas na criação de animais de rebanho, para o trabalho (tração, transporte, adubação) e para o abate com vistas ao aproveitamento da carne (alimento), de outros subprodutos (chifres, couro) e mesmo para fins rituais.

Como se sabe, existem variados registros de populações indígenas nas terras baixas que dispõem de criação bovina, por vezes numerosa e significativa: casos "clássicos" são o dos Kadiweu no Mato Grosso do Sul e dos povos do lavrado de Roraima, como vimos, mas também há rebanhos de menor porte entre os Krahó no Tocantins (MELATTI, 1967), os Tenetehara-Guajajara no Maranhão (GOMES, 2002) e os Bakairi no estado de Mato Grosso (PINA DE BARROS, 2003); em outros países vizinhos há registros de criação bovina entre os Achuar no Equador (DESCOLA, 1982) e os Guajiro (Wayuu) na fronteira entre Colômbia e Venezuela (PICON, 1983), estes um caso especial, bastante bem estudado. Certamente há muitos outros casos, sobretudo de pequenos plantéis, sobre os quais não dispomos de informação. As relações entre estas populações e seus animais de criação, contudo, permanecem em larga medida desconhecidas, não passando, na maior parte das referências bibliográficas, de meras notas sobre a história dos contatos destes grupos com os brancos e seus animais exóticos, e sobre as condições econômicas e as práticas produtivas. Existem apenas alguns poucos estudos que focalizam especificamente a criação/reprodução controlada de animais não nativos entre populações indígenas (Cf. MACDONALD, 1997; MARTINI, 2008), e muito resta ainda por fazer ${ }^{25}$. Praticamente nada sabemos sobre as alterações trazidas

\footnotetext{
${ }^{25}$ Encontram-se, na literatura, algumas breves avaliações de projetos de introdução de criação animal em aldeias na Amazônia e alhures, mas estas não constituem pesquisas detalhadas dos processos, sucessos
} 
FELIPE FERREIRA VANDER VELDEN - Rebanhos em aldeias...

por estes seres nos domínios das técnicas, dos objetos, dos mitos e rituais, e sobre os modos de incorporá-los, criá-los e explorá-los nas aldeias; embora tenhamos algumas indicações de que, em muitos casos, estas não foram de pequena escala, e várias remontam já há séculos, quando do aparecimento e do afluxo das populações não indígenas. Todos esses casos etnográficos demandam a formulação da seguinte pergunta: podemos falar, propriamente, de uma (ou várias) pecuária(s) indígena(s)? E, em caso de resposta afirmativa, uma questão adicional: o que é (são) esta(s) pecuária(s) indígena(s), e como ela(s) se diferencia $(m)$ da pecuária tal como praticada nas sociedades não indígenas no Brasil, rurais e industriais26?

\section{Em Rondônia}

A tarefa que se impõe, portanto, é a de estabelecer as redes através das quais os rebanhos bovinos (principal foco do agronegócio, o que não deve significar a exclusão da investigação de outras espécies) difundiram-se por entre os povos indígenas, atentando para as trajetórias destes movimentos - historicamente, durante os contatos iniciais, e no atual contexto de expansão e intensificação da agropecuária no país, com particular atenção à região amazônica - e para as distintas "modalidades técnicas e ideológicas" de adoção e incorporação desses seres por parte dos grupos que possuem plantéis bovinos de qualquer porte. Pretende-se, portanto, investigar a circulação de animais e de saberes sobre esses animais entre brancos e índios (sejam colonizadores, sejam proponentes de projetos), entre diferentes comunidades indígenas, e no interior dessas próprias comunidades. Devemos, deste modo, reconstituir a história desses animais na Amazônia do ponto de vista dos índios, destacando o que significou a chegada dessas estranhas criaturas e o que significa o

e/ou fracassos de cada um dos casos (Cf. THOMAZ DE ALMEIDA, 2001; SCHRÖDER, 2003; INGLEZ DE SOUZA et al, 2007).

${ }^{26}$ É evidente que, para responder a esta segunda interrogação, deve-se caracterizar detalhadamente a pecuária tal como desenvolvida no ocidente. Isto, claro, por si só demandaria um pesquisa ampla, mas pretendo basear esta reconstituição na literatura disponível sobre a criação e a exploração de animais no mundo rural brasileiro e nas modalidades ditas industriais (intensivas, comerciais, racionais) de criação animal. 
convívio com elas atualmente estabelecido.

Reconstruir a história da penetração do gado na Amazônia brasileira não é tarefa simples, como não é recontar a trajetória da difusão desses animais pela grande floresta: os dados são dispersos e escassos, ou se referem a processos macro econômicos ou macrossociais (as "frentes de ocupação pastoril", por exemplo), nada oferecendo nem das minúcias, nem das interpretações e visões culturalmente distintas, que devem ter feito tão ricos os lentos processos locais de conhecimento, aclimatação e incorporação desses animais em cada aldeia indígena. Um trabalho detalhado como aquele que Virginia DeJohn Anderson (1994, 2002 e 2004) fez sobre a conquista e a colonização britânica na costa nordeste dos atuais Estados Unidos - articulando, a partir da documentação, as grandes modificações ambientais e econômicas trazidas pelos europeus e seus animais domesticados, com as impressões, práticas e ações dos povos indígenas na região com relação a rejeitar, aceitar e/ou acomodar aqueles novos seres, humanos e não humanos - ainda está longe de ter sido feito para terras, povos e contextos brasileiros.

Em linhas gerais, sabemos que, na floresta tropical, os bois não podem se difundir motu proprio, como fizeram ao espalhar-se pelas paisagens abertas do Brasil Centro-Oriental. Assim, as primeiras cabeças de gado na Amazônia são introduzidas, em sua maioria, por missionários a partir do século XVII, e permanecem restritas às circunvizinhanças de povoações e aldeamentos indígenas (GOULART, 1965, p. 28-36; ENGRÁCIA DE OLIVEIRA, 1983, p. 255-257). Deste modo, o gado bovino era conduzido diretamente pelos colonizadores, acompanhando-o, movendo-se após a chegada dos humanos, e não antes deles, como ocorreu nas áreas abertas dos cerrados, caatingas e campos sulinos. O mesmo parece ter ocorrido em Rondônia - dizem os Karitiana que todos os animais exóticos foram trazidos "pela mão do branco"-, mas sabemos ainda menos sobre como este processo de difusão dos animais se desenrolou por lá. Como minhas pesquisas têm sido realizadas naquele estado, discuto particularmente as trajetórias e contextos de aparecimento, difusão e adoção/aclimatação dos bovinos 
em Rondônia 27.

Denise Maldi Meireles (1989, p. 77-82 e 132-140) demonstrou o tráfico intenso de bois (além de pessoas, mercadorias e ideias) na fronteira luso-espanhola do Guaporé, no século XVIII, trazidos para a margem direita do rio, provenientes dos enormes rebanhos guardados pelos aldeamentos que missionários espanhóis fundaram nas regiões de Mojos e Chiquitos, no atual território boliviano. É da Bolívia, também, que começam a chegar bois a partir da segunda metade do século XIX, levados pela nova onda de ocupação do alto vale do rio Madeira e seus grandes afluentes (Jaci-Paraná, Candeias, Jamari, Machado e outros, territórios tradicionais dos Tupi-Arikém) por caucheiros de origem boliviana (TEIXEIRA, 1998). Esses novos colonizadores, abrindo seringais e pastagens, podem ter sido os responsáveis pelos primeiros contatos dos Karitiana não apenas com os brancos, mas também com os animais domesticados trazidos com eles. Com efeito, seus relatos sobre como conheceram vários dos animais exóticos destacam as transformações ambientais provocadas pela presença de invasores brancos:

Tempo antigamente os Karitiana andavam muito longe, lá, outro país, muito longe, não sei onde, [onde tem] americano [sugerindo distância enorme], lá, e viram num campo e vieram para contar que viram anta diferente [bois], veado grande [cavalos ou burros], casa diferente. Voltaram para contar para o povo. Diz que depois Deus [Boty j] ensinou os brancos a criar, e aí os Karitiana viram nas mãos dos brancos esses animais (EPITÁCIO KARITIANA, entrevista em setembro de 2006).

Todos os animais exógenos, dizem, vieram "pela mão do branco". Mas se os bois eram vistos de longe, nas fazendas que começavam a alterar a paisagem regional, outros animais introduzidos - cães, cavalos, galinhas - foram levados diretamente pelos colonizadores brancos, que insistiam em buscar os Karitiana em suas aldeias, no interflúvio entre os rios Candeias e Jaci-Paraná:

\footnotetext{
27 "Rondônia" aqui não se refere apenas ao estado homônimo, mas à grande região drenada pelos formadores do rio Madeira do lado brasileiro (sem incluir a Bolívia), que abrange também o noroeste e parte do leste do Mato Grosso.
} 
FELIPE FERREIRA VANDER VELDEN - Rebanhos em aldeias...

O primeiro homem branco que apareceu na aldeia dos índios se chamava João Chave[s]. Este homem que trouxe a galinha para os índios criar na aldeia. Foi assim que os índios conheceram a galinha; deu nome na língua opok ako. O João Chave[s] trouxe a galinha para o Antônio Moraes criar na aldeia Karitiana. Assim que a galinha foi criada na aldeia Karitiana (WALMIR, GENILDA, MARCOS, SARITA e VALDECIR, entrevista em novembro de 2006).

As narrativas concordam, em geral, que já nos primeiros contatos os Karitiana pediram exemplares desses animais aos brancos com quem intercambiavam. Recebidos juntamente com alimentos, roupas, ferramentas e, sobretudo, sal (Cf. VANDER VELDEN, 2008), é plausível sugerir que esses animais também serviram como mediadores no rápido estabelecimento de relações de trabalho entre os seringalistas que ocupavam a área e os peões Karitiana (MOSER, 1993). De fato, a circulação de animais entre a aldeia e a cidade - que, a meu ver, replica o circuito de seres entre a mata e a aldeia - permanece, hoje, como um dos vínculos duradouros entre os Karitiana e a população não indígena da região, especialmente de Porto Velho: cães, porcos, galinhas e cavalos vêm continuamente das zonas urbanas, ao passo que papagaios e periquitos (em muito menor quantidade, ressalte-se) fazem o caminho inverso; de modo análogo, peixe e caça saem semanalmente de Kyõwã, em demanda dos Karitiana que estão ou vivem na cidade (e servem mesmo para saldar dívidas que os Karitiana contraem ali), ao passo que, no fluxo contrário, frangos congelados e carne bovina fresca - presente de políticos e fazendeiros locais - aparecem com frequência nos veículos que se dirigem para a aldeia.

Penso que a história do aparecimento desses animais exógenos, o processo de adoção desses seres e as redes de circulação de bois (e também cavalos, porcos, galinhas, cães, gatos e outros) que conectam aldeias indígenas, povoados rurais e áreas urbanas em Rondônia, apresentem, em grandes linhas, várias semelhanças. Não obstante, é importante conhecer os detalhes de cada trajetória, assim como descrever os caminhos das transações entre índios e brancos envolvendo animais, bem como as regras que estruturam e organizam estas conexões. Apenas desta forma uma crítica fundamentada das iniciativas e projetos de introdução da criação animal em aldeias poderá 
ser realizada. Aqui, como já destacado, estou interessado sobremaneira nos bois.

Temos informações sobre a presença expressiva de rebanhos bovinos entre os Arara-Karo na Terra Indígena Igarapé Lourdes (Renata Nóbrega, comunicação pessoal), entre os Wari' e entre alguns grupos de língua Tupi-Mondé: os Suruí-Paiter, os Gavião-lkolen, os Cinta Larga e os Zoró (CIMI-RO, 2002). Carlos Coimbra Jr. (1989) apontou alguns dos problemas de ordem sanitária, ambiental e produtiva trazidos pela introdução do gado bovino entre os Suruí-Paiter no Aripuanã, mas não nos oferece dados sobre a inserção destas criaturas na cosmologia daquela sociedade, mesmo tendo-se em vista que a presença de animais de criação nas aldeias Tupi-Mondé e seus efeitos práticos se articulam a certos rituais nos quais esses seres - sejam os introduzidos ou os "nativos" - são, no encerramento, abatidos em massa 28.

Caso mais bem estudado - mas, ainda assim, sobretudo da perspectiva prática, destacando os impactos na saúde e no meio ambiente local - é o dos Wari' (também chamados de Pakaa-Nova), povo de língua Txapakura que vive em cinco áreas indígenas na região do médio-baixo rio Guaporé, oeste de Rondônia, e são aproximadamente 2,7 mil pessoas (LEITE, 2007, p. 33-35). A detalhada história do contato dos diversos subgrupos Wari', efetuada por Aparecida Vilaça (2006), não menciona o aparecimento dos animais exóticos trazidos pelos brancos. Contudo, é razoável supor que a experiência com esses animais tenha sido bastante semelhante àquela descrita por mim para os Karitiana (VANDER VELDEN, 2010a), uma vez que ambos os povos foram atingidos por frentes de colonização muito semelhantes, que percorreram os vales dos rios Guaporé, Madeira e seus grandes afluentes, penetrando a partir de Mato Grosso e da fronteira boliviana. Segundo Maurício Leite (2007, p. 44), várias aldeias Wari' hoje possuem pequenos plantéis bovinos e mesmo alguns currais. $\mathrm{O}$ autor discute alguns aspectos da relação entre os Wari' e seus bois no tocante à alimentação - tópico de sua pesquisa -, mas não dá maiores detalhes sobre a introdução, a inserção material e simbólica, os impactos cotidianos e as práticas relacionadas a esses seres exógenos.

\footnotetext{
${ }^{28}$ Cf. Dal Poz (1991), entre os Cinta Larga que, entretanto, não registra o abate de bois, ainda que exista, hoje ao menos, um pequeno plantel naquela terra indígena.
} 
FELIPE FERREIRA VANDER VELDEN - Rebanhos em aldeias...

Não analisa, por fim, os efeitos práticos e simbólicos da criação de animais destinados, prioritariamente, à alimentação (ao menos na lógica dos brancos), embora sugira, em várias passagens, pistas para futura investigação (LEITE, 2007). Pistas que, inclusive, apontam para conclusões convergentes com aquelas a que cheguei pesquisando os Karitiana.

Por fim, não descartamos a possível existência de pequenos rebanhos bovinos entre outros povos etnograficamente menos conhecidos em Rondônia e regiões circunvizinhas. O fato de que a pecuária cresce a pleno vapor no estado - ocupando mais e mais terras e gerando cada vez mais lucros, diversificando as cadeias produtivas da carne, do leite e de outros produtos -, aliado ao prestígio e ao poder crescentemente vinculados à figura do pecuarista, podem indicar que a presença de bois nas aldeias na região também esteja em expansão. Sugere-o o caso Karitiana e seu desejo insistente pela criação desses animais.

\section{Considerações finais}

O trabalho de investigação que ora se impõe deve, após recensear com a maior precisão possível a presença e o tamanho dos plantéis e as condições de sua manutenção e exploração, retomar esses vários casos, avaliando a posição dos bovinos (e também outros animais exóticos, notadamente cavalos e jumentos, mas também criaturas de menor porte, a criação de pequenos animais) em seu universo cosmológico e material (econômico-produtivo), e investigando os métodos e técnicas de criação envolvidos no tratamento desses grandes ruminantes. Assim, pretende-se delinear as trajetórias de introdução, difusão, aclimatação e adoção dos animais entre diferentes povos indígenas na Amazônia em geral (e em Rondônia, em particular), bem como compreender as modalidades técnicas aplicadas na criação de animais (mais do que aquelas envolvidas no trato com animais de criação, ainda que provavelmente derivadas delas, ou em intenso diálogo com elas) vis-àvis às técnicas e métodos preconizados pelas modernas ciências zootécnicas e veterinárias e pelos saberes locais relativos ao que 
chamei de criação sistemática de animais. Nesta encruzilhada de conhecimentos indígenas das formas de relação prático-simbólica entre humanos e não humanos e os conhecimentos técnico-científicos trazidos pelos brancos - sejam colonos, criadores familiares e grandes pecuaristas, sejam experts acadêmicos, do governo e de outros órgãos públicos e privados -, e que se fundamentam, também eles, em certas premissas da relação entre homens e animais, pretende-se compreender as rotas de difusão, circulação e intercâmbio dos grandes herbívoros exógenos e os processos de negociação, conflito, aprendizado, desejo e acomodação que presidem as relações entre seres humanos e suas espécies companheiras.

\section{Referências bibliográficas}

ANDERSON, Virginia. King Philip's herds: indians, colonists, and the problem of livestock in New England. The William and Mary Quarterly, Williamsburg, v. 51, n. 4, p. 601-624, 1994.

Animals into the wilderness: the development of livestock husbandry in the seventeenth-century Chesapeake. The William and Mary Quarterly, Williamsburg, v. 59, n. 2 , p. $377-408,2002$.

Creatures of empire: how domestic animals transformed early America. Oxford: Oxford University Press, 2004.

BARBOSA, Gabriel. Das trocas de bens. In: GALLOIS, Dominique (Org.). Redes de relações nas Guianas. São Paulo: Humanitas/Fapesp, 2005. p. 59-111.

BARBOSA, Fabiano; MOLINA, Lívio. Conjuntura da carne bovina no mundo e no Brasil. Artigos Científicos do Portal Agronomia, 2007. Disponível em: www.agronomia.com.br/conteudo/artigos . Acesso em: 01 dez. 2009.

BARETTA, Silvio; MARKOFF, John. Civilization and barbarism: cattle frontiers in Latin America. Comparative Studies in Society and History, Cambridge, v. 20, n. 4, p. 587-620, 1978.

BASTOS DA VEIGA, Jonas et al. Expansão e trajetórias da pecuária na Amazônia: Pará, Brasil. Brasília: Ed. da UnB, 2004.

BERTELLI, Antonio. Os fatos e os acontecidos com a poderosa nação dos Índios Cavaleiros Guaycurús no Pantanal do Mato Grosso, entre os anos de 1526 até o ano de 1986. São Paulo: Uyara, 1987. 
FELIPE FERREIRA VANDER VELDEN - Rebanhos em aldeias...

CAPISTRANO DE ABREU, João. Capítulos de história colonial. São Paulo/Belo Horizonte: Edusp/Itatiaia, 1988.

CARNEIRO DA CUNHA, Manuela. Política indigenista no século XIX. In:

(Org.). História dos índios no Brasil. São Paulo: Fapesp/SMC/Cia. das Letras, 1992. p. 133-154.

CIMI-RO. Panewa especial. Porto Velho: CIMI-RO, 2002.

COIMBRA Jr., Carlos. From shifting cultivation to coffee farming: the impact of change on the health and ecology of the Suruí in the Brazilian Amazon. Bloomington: Indiana University, 1989.

CORMIER, Loretta. Kinship with monkeys: the Guajá foragers of eastern Amazonia. New York: Columbia University Press, 2003.

CRONON, William. Changes in the land: indians, colonist, and the ecology of New England. New York: Hill \& Wang, 1983.

CROSBY, Alfred. The Columbiam Exchange: biological and cultural consequences of 1492. Westport: Greenwood Press, 1972.

DAL POZ, João. No país dos Cinta Larga: uma etnografia do ritual. 1991. $361 \mathrm{f}$. Dissertação (Mestrado em Antropologia Social) - FFLCH-USP, [1991].

DESCOLA, Philippe; PÁLSSON, Gísli (Orgs.). Nature and Society: anthropological perspectives. London: Routledge, 1996.

DESCOLA, Philippe. Territorial adjustments among the Achuar of Ecuador. Social Science Information, Amsterdam, v. 21, n. 2, p. 301-320, 1982.

. In the society of nature: a native ecology in Amazonia. Cambridge: Cambridge University Press, 1994.

Commentaire. In: GRUZINSKI, Serge; WACHTEL, Nathan (Orgs.). Le noveau monde, mondes nouveaux. Paris: Éditions Recherche sur les Civilisations/Éditions de l'École des Hautes Études em Sciences Sociales, 1996. pp. 163-167.

Estrutura e sentimento: a relação com o animal na Amazônia. Mana, Rio de Janeiro, v. 4, n. 1, p. 23-45, 1998.

Genealogia dos objetos e antropologia da objetivação. Horizontes Antropológicos, Porto Alegre, v. 8, n. 18, p. 93-112, 2002.

Par-delà nature et culture. Paris: Gallimard, 2005.

Espaço Ameríndio, Porto Alegre, v. 5, n. 1, p. 129-158, jan./jun. 2011. 
FELIPE FERREIRA VANDER VELDEN - Rebanhos em aldeias...

DIGARD, Jean-Pierre. L'homme et les animaux domestiques: Anthropologie d'une passion. Paris: Fayard, 1990.

DONKIN, Robert Arthur. The peccary: with observations on the introduction of pigs to the New World. Philadelphia: The American Philosophical Society, 1985.

The Muscovy Duck, Cairina moschata domestica: origins, dispersal, and associated aspects of the geography of domestication. Rotterdam/Brookfield: A. A. Balkema, 1989.

ENGRÁCIA DE OLIVEIRA, Adélia. Ocupação humana. In: SALATI, Enéas et al (Orgs.). Amazônia: desenvolvimento, integração, ecologia. São Paulo/Brasília: Brasiliense/CNPq, 1983. p. 144-327.

ERIKSON, Philippe. De l'apprivoisement à l'approvisionnement: chasse, alliance et familiarization en Amazonie Amérindienne. Techniques et Cultures, Marseille, v. 9, p. 105-140, 1987.

Apprivoisement et habitat chez les amerindiens Matis (langue Pano, Amazonas, Brésil). Anthropozoologica, Paris, edição especial, p. 211-220, 1988.

Du pécari au manioc ou du riz sans porc? Réflexions sur l'introduction de la riziculture et de l'elevage chez lês Chacobo (Amazonie bolivienne). Techniques et Culture, Marseille, v. 31-32, p. 363-378, 1998.

The social significance of pet keeping among Amazonian Indians. In: PODBERSCEK, Anathony; PAUL, Elizabeth; SERPELL, James (Orgs.). Companion animals and us. Cambridge: Cambridge University Press, 2000. p. 7-26.

EVANS-PRITCHARD, Edward Evan. Os Nuer. São Paulo: Perspectiva, 1999.

FARAGE, Nádia; SANTILLI, Paulo. Estado de sítio: territórios e identidades no vale do rio Branco. In: CARNEIRO DA CUNHA, Manoela (Org.). História dos índios no Brasil. São Paulo: Fapesp/SMC/Cia. das Letras, 1992. p. 267-278.

TI Raposa Serra do Sol: fundamentos históricos. In: MIRAS, Júlia et al. (Orgs.). Makunaima grita! Rio de Janeiro: Azougue, 2009. p. 21-30.

FEARNSIDE, Philip. A ocupação humana de Rondônia: impactos, limites e planejamento. Brasília: Polonoroeste/SCT-PR/CNPq, 1989.

FRANÇOZO, Mariana. De Olinda a Olanda: Johan Maurits van Nassau e a circulação de objetos e saberes no Atlântico Holandês (século XVII). 2009. 296 f. Tese (Doutorado em Ciências Sociais) - Unicamp, [2009].

GALVÃO, Eduardo. O cavalo na América indígena: nota prévia a um estudo de mudança cultural. Revista do Museu Paulista, São Paulo, v. 14, p. 221-232, 1963. 
GILMORE, Raymond. Fauna e etnozoologia da América do Sul tropical. In: RIBEIRO, Berta (Org.). Suma Etnológica Brasileira: Etnobiologia. Belém: Editora Universitária da UFPA, 1997. v. 1. p. 217-277.

GOMES, Mércio. O índio na história: o povo Tenetehara em busca da liberdade. Petrópolis: Vozes, 2002.

GORDILLO, Gastón. ¿Formas modernas de caza y recoleción?. In: En el Gran Chaco: antropologías y historias. Buenos Aires: Prometeo Libros, 2006. p. 277-296.

GOULART, José Alípio. O Brasil do boi e do couro. Rio de Janeiro: Edições GRD, 1965.

GUERRA, Emerson. Organização política e segurança alimentar na sociedade Krahô. Uberlândia: Edufu, 2008.

HARAWAY, Donna. When species meet. Minneapolis: University of Minnesota Press, 2003.

The companion species manifesto: dogs, people, and significant otherness. New York: Pricly Paradigm Press, 2008.

HECHT, Susanna. The logic of livestock and deforestation in Amazonia. BioScience, Uberlândia, v. 43, n. 10, p. 687-695, 1993.

INGOLD, Tim. The perceptions of environment: essays on livelihood, dwelling, and skill. New York: Routledge, 2000.

INGLEZ DE SOUZA, Cássio et al (Orgs.). Povos indígenas: projetos e desenvolvimento. Rio de Janeiro: Contra Capa, 2007.

ISA; MOREAU, Alain. Parceria pecuária em terra indígena: a novidade Kadiwéu. In: INSTITUTO SOCIOAMBIENTAL. Povos indígenas no Brasil: 1996-2000. São Paulo: Instituto Socioambiental, 2000. p. 749-753.

JARA, Fabíola. The meaning of nominal animal categories among the Caribs of the Guianas. Anthropos, Fribourg, v. 97, n. 1, p. 117-126, 2002.

KNIGHT, John (Org.). Animals in person: cultural perspectives on human-animal intimacies. Oxford: Berg, 2005.

KOHN, Eduardo. How dogs dream: Amazonian natures and the politics of transspecies. American Ethnologist, Washington, v. 34, n. 1, p. 3-24, 2007.

LATOUR, Bruno. Jamais fomos modernos: ensaio de antropologia simétrica. Rio de Janeiro: Ed. 34, 1997.

Políticas da natureza: como fazer ciência na democracia. Bauru: Edusc, 
2004.

LEACH, Edmund. Aspectos antropológicos da linguagem: categorias animais e insulto verbal. In: DAMATTA, Roberto (Org.). Edmund Leach: Antropologia. São Paulo: Ed. Ática, 1983. p. 170-198.

LEITE, Maurício. Transformação e persistência: antropologia da alimentação e nutrição em uma sociedade indígena Amazônica. Rio de Janeiro: Ed. da Fiocruz, 2007.

LÉVI-STRAUSS, Claude. Tristes trópicos. São Paulo: Cia. das Letras, 1996.

O pensamento selvagem. Campinas: Papirus, 1997.

A lição de sabedoria das vacas loucas. Novos Estudos CEBRAP, São Paulo, n. 70, p. 79-84, 2004.

LORENZ, Konrad. E o homem encontrou o cão... Lisboa: Relógio d’Água Editores, 1997.

MACDONALD, Theodore. De cazadores a ganaderos. Quito: Abya-Yala, 1997.

MACÊDO, Silvia Lopes. Encantamento do boi e reis encantados: xamanismo e identidade étnica entre os índios Kiriri do sertão baiano. 2006. 66 f. Monografia (Graduação em Ciências Sociais) - UFBA, [2006].

MARCHANT, Alexandre. Do escambo à escravidão: as relações econômicas de portugueses e índios na colonização do Brasil, 1500-1580. São Paulo: Cia. Editora Nacional, 1943.

MARTINI, André. Filhos do homem: a introdução da piscicultura entre populações indígenas no povoado de Iauaretê, rio Uaupés. 2008. 158 f. Dissertação (Mestrado em Antropologia Social) - Unicamp, [2008].

MEIRELES, Denise Maldi. Guardiães da fronteira: Rio Guaporé, século XVIII. Petrópolis: Vozes, 1989.

MELATTI, Júlio Cesar. Índios e criadores: a situação dos Krahó na área pastoril do Tocantins. Rio de Janeiro: ICS-UFRJ, 1967.

MELVILLE, Elinor. A plague of sheep: environmental consequences of the conquest of Mexico. Cambridge: Cambridge University Press, 1999.

METCALF, Alida. Go-betweens and the colonization of Brazil: 1500-1600. Austin: University of Texas Press, 2005.

NORDENSKIÖLD, Erland. Deductions suggested by the geographical distribution of some post-Columbian words used by the Indians of South America. Göteborg: Elanders Boktryckeri Aktiebolag, 1922. 
MOSER, Lilian. Os Karitiana e a colonização recente em Rondônia. 1993. 190 f. Monografia (Graduação em História) - UNIR, [1993].

OVERING, Joanna. Elogio do cotidiano: a confiança e a arte da vida social em uma comunidade amazônica. Mana, Rio de Janeiro, v. 5, n. 1, p. 81-107, 1999.

PALERMO, Miguel Angel. Reflexiones sobre el llamado 'complejo ecuestre' en la Argentina. Runa, Buenos Aires, v. 16, p. 157-178, 1986.

PICON, François-René. Pasteurs du Nouveau Monde: adoption de l'élevage chez les Indiens Guajiros. Paris: Éditions de la Maison des Sciences de l'Homme, 1983.

PINA DE BARROS, Edir. Os filhos do sol: história e cosmologia na organização social de um povo Karib, os Kurâ-Bakairi. São Paulo: Edusp, 2003.

PODBERSCEK, Anathony; PAUL, Elizabeth; SERPELL, James (Orgs.). Companion animals and us. Cambridge: Cambridge University Press, 2000.

QUEIXALÓS, Francisco. Les mythes et les mots de l'identité Sikuani. In: BECQUELIN, Aurore; MOLINIÉ, Antoinette (Orgs.). Mémoire de la tradition. Nanterre: Société d'Ethnologie, 1993. p. 71-106.

RAMOS, Alcida. Projetos indigenistas no Brasil independente. Brasília: DAN-UnB, 1999. (Coleção Antropologia, 267).

RIBEIRO, Darcy. Os índios e a civilização: a integração das populações indígenas no Brasil moderno. São Paulo: Cia. das Letras, 1996.

RIBEIRO DE ALMEIDA, Fábio Vaz (Org.). Guia para a formação em gestão de projetos indígenas. Brasília: Paralelo 15/Esplanada dos Ministérios, 2008.

ROBBINS, Louise. Elephant slaves and pampered parrots: exotic animals in eighteenth-century Paris. Baltimore: The Johns Hopkins University Press, 2002.

ROTHFELS, Nigel (Org.). Representing animals. Bloomington: University of Indiana Press, 2002.

SAHLINS, Marshall. Ilhas de História. Rio de Janeiro: Zahar, 1985.

Cultura e razão prática. Rio de Janeiro: Jorge Zahar Editor, 2003.

SALGADO, Carlos Bezerra. Segurança alimentar e nutricional em terras indígenas. Revista de Estudos e Pesquisas (FUNAI), Brasília, v. 4, n. 1, p. 131-186, 2007.

SANTILLI, Paulo. As fronteiras da República: história e política entre os Macuxi no vale do rio Branco. São Paulo: NHII-USP/FAPESP, 1994. 
FELIPE FERREIRA VANDER VELDEN - Rebanhos em aldeias...

SCHRÖDER, Peter. Economia indígena: situação atual e problemas relacionados a projetos indígenas de comercialização na Amazônia Legal. Recife: Editora Universitária da UFPE, 2003.

SCHWARTZ, Marion. A history of dogs in early Americas. New Haven: Yale University Press, 1997.

SERPELL, James. In the company of animals: a study of human-animal relationships. Cambridge: Cambridge University Press, 1996.

SHANKLIN, Eugenia. Sustenance and symbol: anthropological studies of domesticated animals. Annual Review of Anthropology, Palo Alto, v. 14, p. 375-403, 1985.

SIQUEIRA Jr., Jaime. Arte e técnica Kadiwéu. São Paulo: SMC, 1992.

SMERALDI, Roberto; MAY, Peter. O reino do gado: uma nova fase na pecuarização da Amazônia. São Paulo: Amigos da Terra - Amazônia Brasileira, 2008.

A hora da conta: pecuária, Amazônia e conjuntura. São Paulo: Amigos da Terra - Amazônia Brasileira, 2009.

SOUZA LIMA, Antonio Carlos de. Um grande cerco de paz. Petrópolis: Vozes, 1995.

TAMBIAH, Stanley. Animals are good to think and good to prohibit. Ethnology, Viena, v. 8, n. 4, p. 423-459. 1969.

TEIXEIRA, Marco Antônio D. Mortos, dormentes e febris: um estudo sobre o medo, a morbidade e a morte nos vales do Guaporé e Madeira, entre os séculos XVIII e XX. In: PREFEITURA MUNICIPAL DE PORTO VELHO (Org.). Porto Velho conta a sua história. Porto Velho: SEMCE/PMPV, 1998. p. 99-155.

THOMAS, Keith. O homem e o mundo natural: mudanças de atitude em relação às plantas e aos animais (1500-1800). São Paulo: Cia. das Letras, 2001.

THOMAZ DE ALMEIDA, Rubem. Do desenvolvimento comunitário à mobilização política: o Projeto Kayowá-Ñandeva como experiência antropológica. Rio de Janeiro: Contra Capa, 2001.

TONI, Fabiano et al. Expansão e trajetórias da pecuária na Amazônia: Acre, Brasil. Brasília: Ed. da UnB, 2007.

TURBAY, Sandra. Aproximaciones a los estúdios antropológicos sobre la relación entre el ser humano y los animales. In: ULLOA, Astrid. (Org.). Rostros culturales de la fauna: las relaciones entre los humanos y los animales em el contexto colombiano. Bogotá: INAH/Fundación Natura, 2002. p. 87-111.

VANDER VELDEN, Felipe. O GOSTO DOS OUTROS: o sal e a transformação dos 
corpos entre os Karitiana no sudoeste da Amazônia. Temáticas, Campinas, v. 16, n. 31-32, p. 13-49, 2008.

Inquietas companhias: sobre os animais de criação entre os Karitiana. 2010a. 325 f. Tese (Doutorado em Antropologia Social) - Unicamp, [2010a]

Dizem que comem, mas não comem: alimentação, familiarização e criação animal entre os Karitiana em Rondônia. Belém: XXVII Reunião Brasileira de Antropologia, 2010b.

As galinhas incontáveis: Tupis, europeus e aves domésticas na conquista do Brasil. No prelo. 2010c.

VILAÇA, Aparecida. Quem somos nós?: Os Wari' encontram os brancos. Rio de Janeiro: Editora UFRJ, 2006.

VIVEIROS DE CASTRO, Eduardo. Os pronomes cosmológicos e o perspectivismo ameríndio. Mana, Rio de Janeiro: v. 2, n. 2, p. 115-144, 1996.

Imagens da natureza e da sociedade. In: A inconstância da alma selvagem e outros ensaios de antropologia. São Paulo: Cosac Naify, 2002. p. 317344. 